\title{
Functional outcome following a locked fracture-dislocation of the calcaneus
}

\author{
Tim Schepers • Manouk Backes • Niels W. L. Schep • \\ J. Carel Goslings • Jan S. K. Luitse
}

Received: 9 July 2013 / Accepted: 31 July 2013 /Published online: 21 August 2013

(C) Springer-Verlag Berlin Heidelberg 2013

\begin{abstract}
Purpose Locked fracture-dislocations of the calcaneus are uncommon, and a substantial number of these injuries is not recognised or is misdiagnosed at first presentation. The primary aim of this study was to evaluate the long-term outcome in patients with this injury.

Methods This is a retrospective cohort study of adult patients who sustained a uni- or bilateral calcaneal fracturedislocation. Outcome was measured using validated questionnaires, including the American Orthopaedic Foot and Ankle Society Hindfoot score (AOFAS), Foot Function Index (FFI) and a visual analogue scale (VAS).

Results During the 12-year study period a total of 16 patients with 17 locked fracture-dislocations were identified. This represented $6 \%$ of all surgically treated calcaneal fractures (17 of 279). The median follow-up was 48 months. All patients were treated using an extended lateral approach and plate fixation. In one patient with a delayed presentation a primary arthrodesis was performed. The functional outcome scores were available for 14 patients with 14 fractures. The median AOFAS was 74 [interquartile range (IQR) 47-86], the median FFI was 18 (IQR 6-37) and the median VAS for overall satisfaction was 8.2 (IQR 5.5-9.4). A secondary fusion was deemed necessary in three cases.

Conclusions This study shows that, with surgical treatment via an extended lateral approach, the outcome in patients with a locked fracture-dislocation of the calcaneus is similar to the outcome of other displaced intra-articular calcaneal fracture
\end{abstract}

Tim Schepers and Manouk Backes contributed equally to this work.

T. Schepers $(\bowtie) \cdot$ M. Backes $•$ N. W. L. Schep · J. C. Goslings

J. S. K. Luitse

Trauma Unit, Department of Surgery, Academic Medical Center,

Meibergdreef 9, PO Box 22660, 1100 DD Amsterdam,

The Netherlands

e-mail: t.schepers@amc.nl types. However, a higher rate of secondary subtalar fusion can be expected.

Keywords Calcaneus · Fracture-dislocation · Outcome · Arthrodesis

\section{Introduction}

Locked fracture-dislocations of the calcaneus are uncommon, and a substantial number of these injuries is not recognised or is misdiagnosed at first presentation [1, 2]. In locked fracturedislocations the posterolateral joint fragment of the subtalar joint is positioned laterally from the talus or even wedged inbetween the talus and the lateral malleolus. This type of injury occurs due to an axial force with the hindfoot inverted [1]. When subsequently the lateral calcaneofibular ligaments rupture or the distal fibula fractures, the posterolateral segment of the calcaneus can dislocate including a portion of the posterior talocalcaneal joint [3].

There is consensus in the literature that the optimal treatment for patients with locked fracture-dislocations of the calcaneus is operative management. However, the available studies included only a small number of patients. Secondly, most of these series lack the use of a functional outcome scoring system [1-5].

The primary aim of this study was to evaluate the long-term outcome of patients with locked fracture-dislocations of the calcaneus. Secondly, the patient and fracture characteristics of locked fracture-dislocations of the calcaneus were evaluated.

\section{Methods}

This study is a retrospective cohort study of all consecutive adult patients who sustained a uni- or bilateral calcaneal fracture between 1 January 2000 and 31 December 2011. All patients with displaced intra-articular calcaneal fractures 
were treated operatively. An electronic database was searched for all patients with calcaneal fractures using the appropriate surgical codes. A total of 248 patients with 279 calcaneal fractures were treated operatively in this period.

All conventional radiographs and computed tomography (CT) scans were evaluated to identify all consecutive patients with a locked fracture-dislocation. A locked fracturedislocation was defined as a dislocation of the posterolateral portion of the calcaneus including a part of the posterior joint fragment lateral to the talus, wedged between the lateral talar process and the lateral malleolus on the axial and (semi-)coronal reconstructions of the CT scan (Figs. 1, 2 and 3).

Data obtained from the medical charts and electronic radiographic viewer (IMPAX, Agfa HealthCare 2011) were gathered in a SPSS version 18 database (SPSS Inc., Chicago, IL, USA). Patient-related items were: gender, age at trauma, trauma mechanism and Injury Severity Score (ISS). Fracture characteristics were: presence of varus tilt of the talus [1], double density sign $[4,6]$, the involvement of the calcaneocuboid joint (CCJ) [7, 8], associated fibula fracture [2] and Essex-Lopresti and Sanders classification (Fig. 1). Surgical characteristics included were surgical delay and need for secondary subtalar arthrodesis.

Outcome was measured using validated questionnaires, which were sent by post in April 2013 after a minimum follow-up of 18 months, and consisted of the American Orthopaedic Foot and Ankle Society Hindfoot score (AOFAS) [9], Foot Function Index (FFI) [10] and a visual analogue scale (VAS). The AOFAS score includes nine questions related to three components: pain (one question, 40 points), function (seven questions, 50 points) and alignment (one question, 10 points) leading to a best score of 100 points. The questions related to alignment and range of motion were completed by a physician based upon patient files and radiographs; the other questions were completed by the patient. The FFI consists of 23 questions to measure the impact of foot pathology on function in terms of pain, disability and restriction of activity. A lower score indicates a better outcome. Finally, a VAS was used to measure overall satisfaction of patients (range $0-10$ ).

\section{Statistics}

Data were analysed using the PASW Statistics version 18.0 (SPSS Inc., Chicago, IL, USA). Normality of continuous data was tested with the Kolmogorov-Smirnov test and by inspecting the frequency distributions (histograms). Descriptive analysis was performed to assess baseline characteristics. For continuous data mean $\pm \mathrm{SD}$ (parametric data) or medians with interquartile ranges (IQR, non-parametric data) were calculated. Differences were assessed using Student's $t$ test (parametric data) or the Mann-Whitney U test (non-parametric data). Categorical data were compared using the chisquare test. A $p$ value $<0.05$ was taken as the threshold of statistical significance.

\section{Results}

During the study period a total of 16 patients with 17 locked fracture-dislocations were identified (Table 1). This represented $6.1 \%$ of all surgically treated calcaneal fractures (17 of 279).

There were 11 (67\%) male patients and five (33\%) female patients (Figs. 2 and 3). The median age at trauma was 43 years (IQR 36-57). The patients were operated upon, on average, after 13 days (range seven to 16). Two patients were polytrauma patients with an ISS of 16 or more (13\%). Eleven fractures were of the right calcaneus. The trauma mechanism was a fall from height in 11 (69\%), fall from stairs in four $(25 \%)$ and a twisting injury in one $(6 \%)$. The median follow-up was 48 months (IQR 27-105).

Twelve fracture-dislocations were classified as an EssexLopresti tongue-type and five as joint depression. The Sanders classification showed 12 type II injuries (nine IIA, three IIB) and five type III fractures (1 IIIAB, 4 IIIBC). All fractures were closed injuries.

Varus tilt on the anteroposterior ankle view was present in ten of $17(59 \%)$ fracture-dislocations. The cases where varus tilt of the talus was not present were all Sanders type II (six Sanders type IIA, one type IIB) fractures $(p=0.09)$. The double density sign was visible in 16 of 17 cases $(94 \%)$.
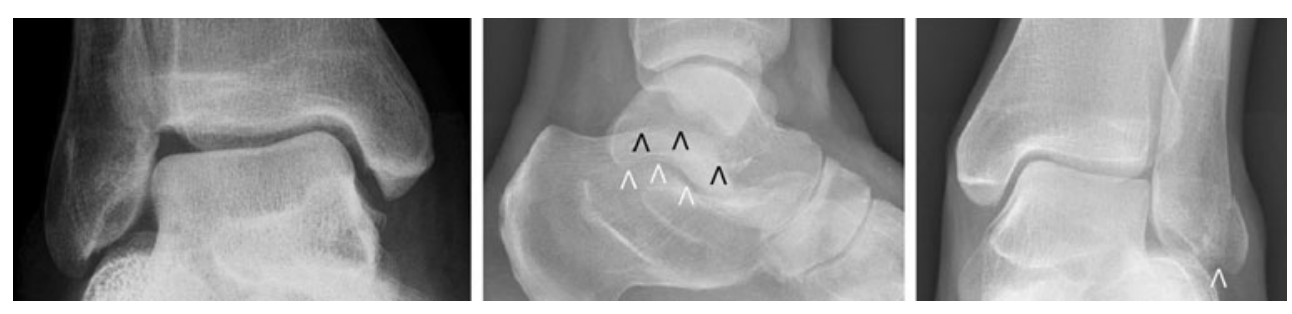

Fig. 1 Radiographic characteristics of a locked fracture-dislocation of the calcaneus. a Varus tilt of the talus on the ankle mortise view. b Double density sign on the lateral foot view (black arrowheads: density of lateral joint fragment of calcaneus, white arrowheads : density of lower border of talus). c Associated distal fibula fracture (white arrowhead) 
Fig. 2 Radiographic and CT appearance in patient 7. a Lateral view with double density sign, $\mathbf{b}$ anteroposterior view with varus tilt, $\mathbf{c}$ axial CT scan image showing Sanders type IIIBC fracture-dislocation, $\mathbf{d}$ coronal view of fracture-dislocation

Fig. 3 Radiographic and CT appearance in patient 9 . a Lateral view with double density sign, $\mathbf{b}$ anteroposterior view without varus tilt, $\mathbf{c}$ axial CT scan image showing Sanders type IIA fracture-dislocation, $\mathbf{d}$ coronal view of fracture-dislocation
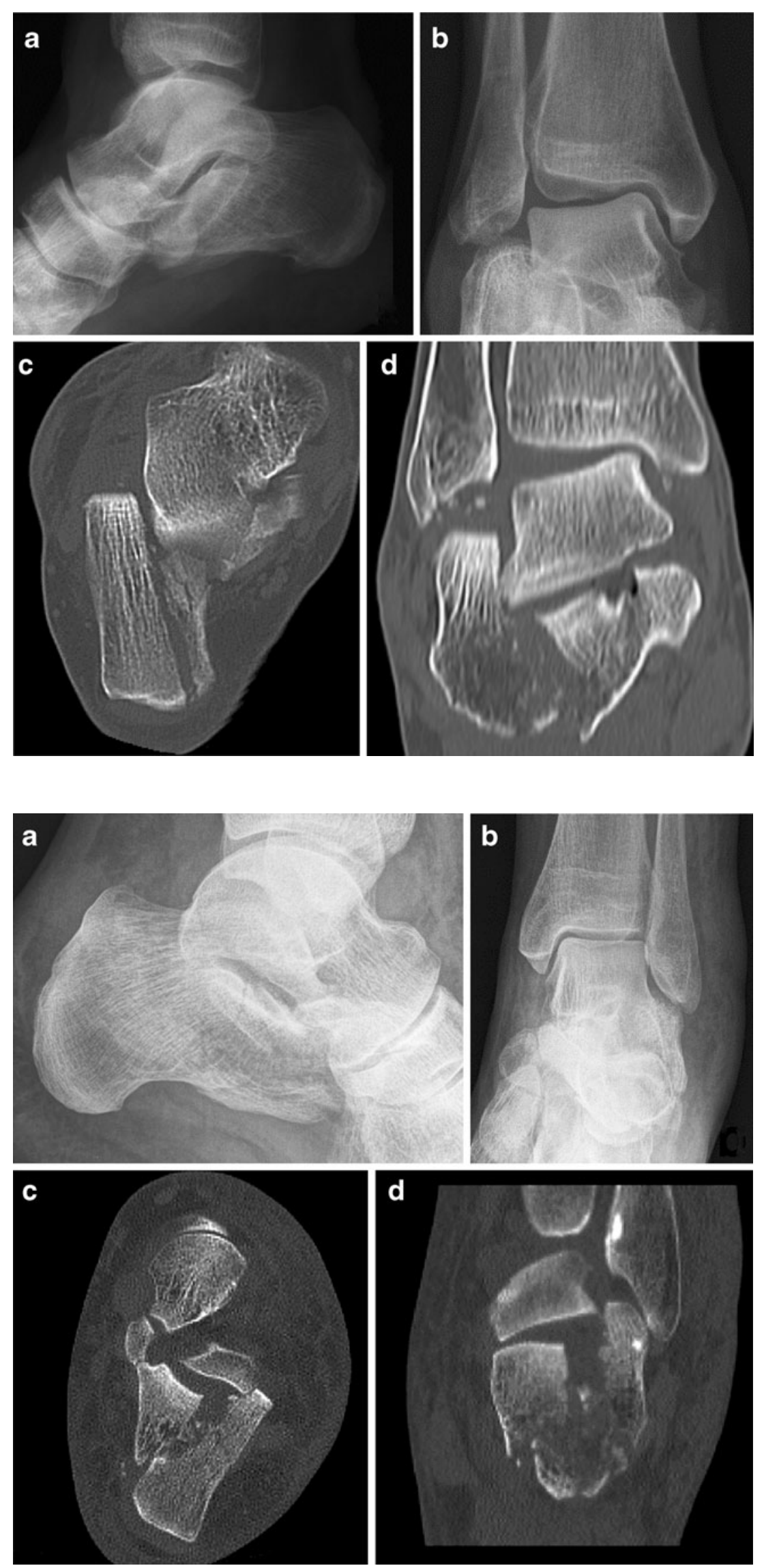
Table 1 Patient and radiographic characteristics in locked fracture-dislocations of the calcaneus

\begin{tabular}{|c|c|c|c|c|c|c|c|c|c|c|c|c|c|c|}
\hline Patient & Gender & $\begin{array}{l}\text { Age at } \\
\text { trauma }\end{array}$ & $\begin{array}{l}\text { Trauma } \\
\text { mechanism }\end{array}$ & Side & $\begin{array}{l}\text { Talar } \\
\text { tilt }\end{array}$ & $\begin{array}{l}\text { Double } \\
\text { density }\end{array}$ & $\begin{array}{l}\text { CCJ } \\
\text { involvement }\end{array}$ & $\begin{array}{l}\text { Fibula } \\
\text { fracture }\end{array}$ & $\begin{array}{l}\text { Essex- } \\
\text { Lopresti }\end{array}$ & Sanders & Treatment & AOFAS & FFI & VAS \\
\hline 1 & M & 56 & Fall $2.5 \mathrm{~m}$ & $\mathrm{R}$ & $\mathrm{Y}$ & $\mathrm{Y}$ & $>2 \mathrm{~mm}$ & $\mathrm{Y}$ & Tongue & IIIAB & ORIF & 34 & 38 & 5.5 \\
\hline 2 & $\mathrm{~F}$ & 43 & Fall $3 \mathrm{~m}$ & $\mathrm{R}$ & $\mathrm{N}$ & $\mathrm{N}$ & $\mathrm{N}$ & $\mathrm{N}$ & JD & IIA & ORIF & 56 & 44 & 5 \\
\hline 3 & M & 41 & Fall & $\mathrm{R}+\mathrm{L}$ & $\mathrm{Y} / \mathrm{N}$ & $\mathrm{Y} / \mathrm{Y}$ & $<2 \mathrm{~mm}$ & $\mathrm{~N} / \mathrm{N}$ & Tongue & IIB/IIA & ORIF & NA & NA & NA \\
\hline 4 & $\mathrm{~F}$ & 66 & Fall & $\mathrm{R}$ & $\mathrm{N}$ & $\mathrm{Y}$ & $<2 \mathrm{~mm}$ & $\mathrm{Y}$ & Tongue & IIA & Sec STA & 40 & 37 & 5 \\
\hline 5 & M & 43 & Fall $2 \mathrm{~m}$ & $\mathrm{R}$ & $\mathrm{N}$ & $\mathrm{Y}$ & $<2 \mathrm{~mm}$ & $\mathrm{~N}$ & Tongue & IIA & ORIF & 85 & 2 & 8 \\
\hline 6 & M & 35 & Fall & $\mathrm{R}$ & $\mathrm{Y}$ & $\mathrm{Y}$ & $<2 \mathrm{~mm}$ & $\mathrm{~N}$ & Tongue & IIIBC & ORIF & 90 & 4 & 10 \\
\hline 7 & $\mathrm{~F}$ & 56 & Fall stairs & $\mathrm{R}$ & $\mathrm{Y}$ & $\mathrm{Y}$ & $>2 \mathrm{~mm}$ & $\mathrm{~N}$ & Tongue & IIIBC & ORIF & 80 & 16 & 9.3 \\
\hline 8 & $\mathrm{~F}$ & 60 & Fall ladder & $\mathrm{L}$ & $\mathrm{Y}$ & $\mathrm{Y}$ & $>2 \mathrm{~mm}$ & $\mathrm{Y}$ & Tongue & IIA & ORIF & 100 & 0 & 10 \\
\hline 9 & $\mathrm{~F}$ & 65 & Fall stairs & $\mathrm{L}$ & $\mathrm{N}$ & Y & $>2 \mathrm{~mm}$ & $\mathrm{~N}$ & Tongue & IIA & ORIF & 75 & 11 & 7 \\
\hline 10 & M & 32 & Fall $6 \mathrm{~m}$ & $\mathrm{~L}$ & Y & $\mathrm{Y}$ & $>2 \mathrm{~mm}$ & Y & JD & IIIBC & Sec STA & 24 & 53 & 8.3 \\
\hline 11 & M & 29 & Fall 4 m & $\mathrm{L}$ & $\mathrm{N}$ & Y & $<2 \mathrm{~mm}$ & $\mathrm{~N}$ & Tongue & IIB & ORIF & 64 & 39 & 0 \\
\hline 12 & M & 54 & Fall stairs & $\mathrm{R}$ & Y & $\mathrm{Y}$ & $<2 \mathrm{~mm}$ & Y & Tongue & IIB & ORIF & 75 & 15 & 10 \\
\hline 13 & M & 47 & Fall & $\mathrm{L}$ & $\mathrm{N}$ & Y & $<2 \mathrm{~mm}$ & $\mathrm{~N}$ & JD & IIA & ORIF & 72 & 46 & 8.3 \\
\hline 14 & M & 40 & Fall $6 \mathrm{~m}$ & $\mathrm{R}$ & Y & $\mathrm{Y}$ & $\mathrm{N}$ & $\mathrm{N}$ & Tongue & IIA & ORIF & 88 & 6 & 8.7 \\
\hline 15 & M & 37 & Distorsion & $\mathrm{R}$ & Y & $\mathrm{Y}$ & $\mathrm{N}$ & $\mathrm{N}$ & JD & IIA & Prim STA & 49 & 31 & 8 \\
\hline 16 & M & 41 & Fall $6 \mathrm{~m}$ & $\mathrm{~L}$ & $\mathrm{Y}$ & $\mathrm{Y}$ & $>2 \mathrm{~mm}$ & Y & JD & IIIBC & ORIF & NA & NA & NA \\
\hline
\end{tabular}

$J D$ joint depression, $C C J$ calcaneocuboid joint, ORIF open reduction internal fixation, AOFAS American Orthopaedic Foot and Ankle Society Hindfoot score, FFI Foot Function Index, VAS visual analogue scale, Sec/Prim STA secondary/primary subtalar arthrodesis following ORIF

Six patients had a concomitant distal fibula fracture (35\%). None of the radiographic findings were statistically significantly influenced by the fracture classification of Sanders or Essex-Lopresti.

\section{Surgical procedure}

All patients were treated using an extended lateral approach. In one delayed case a primary arthrodesis with $7.3-\mathrm{mm}$ cannulated screws was performed following open reduction and internal fixation. All other fractures were stabilised using a stainless steel non-locking calcaneal plate with stainless steel 3.5-mm screws (Fig. 4). Of six patients with a substantial avulsion fracture of the fibula, two interfered with the peroneal tendons and were reattached including the lateral ankle ligaments via the same extended lateral approach (patients 10 and 16).

Functional outcome scores were available for 14 patients with 14 fractures. The median AOFAS was 74 (IQR 47-86), the median FFI was 18 (IQR 6-37) and the median VAS for overall satisfaction was 8.2 (IQR 5.5-9.4). One patient (case 15 ) was referred to us with a delay in diagnosis of almost three months. In this patient a primary subtalar arthrodesis was performed. Two patients (cases 4 and 10) eventually needed a secondary arthrodesis and in one case (patient 11) a secondary procedure is planned (total three of 16 fractures, $19 \%$ ).
Fig. 4 Post-operative images following a locked fracturedislocation. a Lateral view, b Broden's view
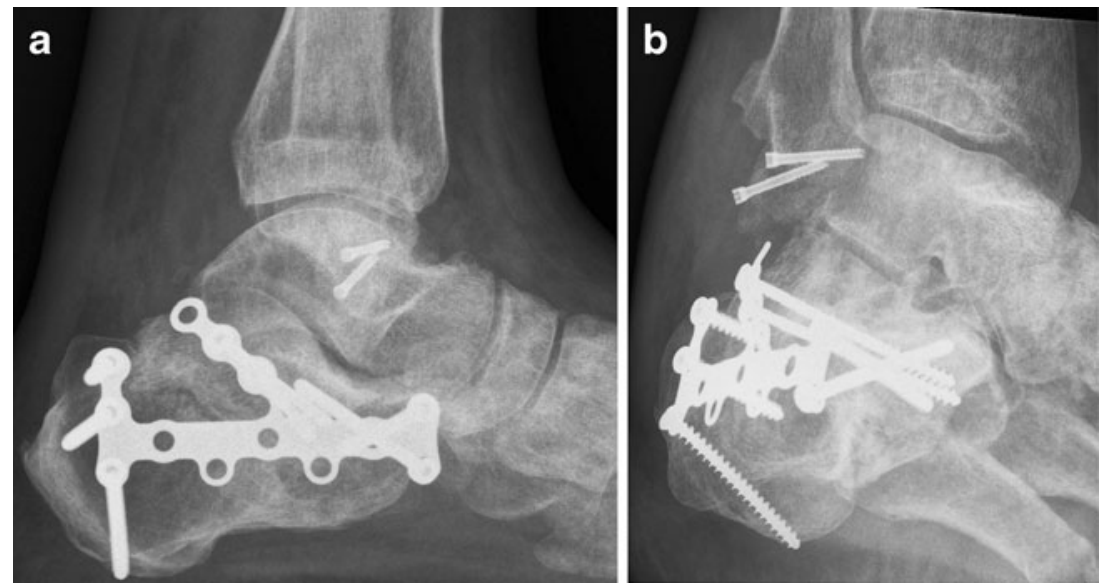


\section{Discussion}

Recent literature on surgical treatment of displaced intraarticular calcaneal fractures without locked fracturedislocation using both the AOFAS and the FFI shows results similar to our study [11-15]. We identified one previous study that included a functional outcome scoring system to evaluate the results of locked fracture-dislocations [16]. The authors described the injury as an intra-articular calcaneal fracture with lateral subluxation of the posterior facet, fracture extension into the CCJ, peroneal tendon subluxation and subluxation of the talus in the ankle mortise, with either complete disruption of the anterior talofibular and calcaneal fibular ligaments or fracture of the lateral malleolus [16]. With an average follow-up of 26 months the AOFAS score in this study was 80 points in 11 patients (representing $8.7 \%$ of their population of surgically treated calcaneal fractures).

There are some marked differences between this study and our study. Even though the AOFAS scores were not that different we performed or planned a secondary fusion in one of five of these patients, as Ebraheim et al. did not perform any arthrodeses [16]. This difference might have to do with the follow-up which was twice as long in our study. Secondly, the definition used by Ebraheim et al. of a locked fracturedislocation did not hold true in some of our patients. For example, in CT scan-confirmed locked fracture-dislocation three of 17 did not have CCJ involvement and 7 of $17 \mathrm{did}$ not show varus tilt of the talus.

These findings implicate that the functional outcome following surgical treatment using an extended lateral approach is similar to the outcome of intra-articular calcaneal fractures without locked fracture-dislocation of the posterolateral fragment. It should however be noted that in this small series the rate of a secondary arthrodesis of three of $16(19 \%)$ fractures is considerably higher than in most series on surgical treatment of displaced intra-articular calcaneal fractures, which might reflect that the locked fracture-dislocation can be considered a more severe injury.

Varus tilt of the talus due to a calcaneal fracture was reported by Jimeno-Vidal in 1960 and later by Carr in 1991 $[1,4]$. The injury reported in this case was an initially unrecognised fracture-dislocation managed conservatively, resulting in a poor outcome. The cause of the talar tilt has been reported to be due to the rupture of the lateral ankle ligaments with or without the combination of a distal fibular fracture [7]. With the talus remaining attached to the sustentaculum the tuberosity displaces into varus as the lateral fragment dislocates lateral to the talus and behind the distal fibula [1]. In our study the locked fracture-dislocations not displaying a varus tilt were all Sanders type II, of which only one was not a Sanders type IIA. This might implicate that in order to create varus tilt the dislocated lateral fragment needs to be of sufficient width to push the talus into varus.
The double density sign in relation to the locked fracturedislocation is due to the superior dislocation of the fracture fragment, which is visible as a second density located superior to the sustentaculum overlapping with the talus $[4,6]$. In $94 \%$ of our cases a double density sign was visible. Therefore a double density sign is the most predictive finding in the locked fracture-dislocation injury.

In conclusion, locked fracture-dislocations are rare injuries. The dislocation is irreducible by conservative measures, leaving no place for conservative treatment in this type of calcaneal fracture. Our study shows that the patient-related outcome of locked calcaneal fractures is similar to the outcome of other displaced intra-articular calcaneal fracture types. However, a higher rate of secondary subtalar arthrodesis can be expected.

\section{References}

1. Carr JB (1991) Varus of the talus in the ankle mortise secondary to calcaneus fracture. A case report. Clin Orthop Relat Res 263:206209

2. Eastwood DM, Maxwell-Armstrong CA, Atkins RM (1993) Fracture of the lateral malleolus with talar tilt: primarily a calcaneal fracture not an ankle injury. Injury 24:109-112

3. Court-Brown CM, Boot DA, Kellam JF (1986) Fracture dislocation of the calcaneus. A report of two cases. Clin Orthop Relat Res 213:201-206

4. Jimeno-Vidal F (1960) Isolated fracture of the sustentaculum tali with outward luxation of the calcaneus. Z Orthop Ihre Grenzgeb 93:30-46

5. Turner NS, Haidukewych GJ (2003) Locked fracture dislocation of the calcaneus treated with minimal open reduction and percutaneous fixation: a report of two cases and review of the literature. Foot Ankle Int 24:796-800

6. Kim DH, Berkowitz MJ (2012) Double density sign variant in fracture-dislocation of the calcaneus: clinical tip. Foot Ankle Int 33:524-525

7. Ebraheim NA, Savolaine ER, Paley K, Jackson WT (1993) Comminuted fracture of the calcaneus associated with subluxation of the talus. Foot Ankle 14:380-384

8. Kinner B, Schieder S, Müller F, Pannek A, Roll C (2010) Calcaneocuboid joint involvement in calcaneal fractures. J Trauma 68:1192-1199

9. Kitaoka HB, Alexander IJ, Adelaar RS, Nunley JA, Myerson MS, Sanders M (1994) Clinical rating systems for the ankle-hindfoot, midfoot, hallux, and lesser toes. Foot Ankle Int 15:349-353

10. Budiman-Mak E, Conrad KJ, Roach KE (1991) The Foot Function Index: a measure of foot pain and disability. J Clin Epidemiol 44:561-570

11. Basile A (2012) Subjective results after surgical treatment for displaced intra-articular calcaneal fractures. J Foot Ankle Surg 51:182-186

12. Ibrahim T, Rowsell M, Rennie W, Brown AR, Taylor GJ, Gregg PJ (2007) Displaced intra-articular calcaneal fractures: 15-year followup of a randomised controlled trial of conservative versus operative treatment. Injury 38:848-855

13. Kline AJ, Anderson RB, Davis WH, Jones CP, Cohen BE (2013) Minimally invasive technique versus an extensile lateral approach for intra-articular calcaneal fractures. Foot Ankle Int 34:773-780 
14. Potter MQ, Nunley JA (2009) Long-term functional outcomes after operative treatment for intra-articular fractures of the calcaneus. J Bone Joint Surg Am 91:1854-1860

15. Zhang J, Ebraheim N, Lausé GE, Xiao B, Xu R (2012) A comparison of absorbable screws and metallic plates in treating calcaneal fractures: a prospective randomized trial. J Trauma Acute Care Surg 72:E106-E110

16. Ebraheim NA, Elgafy H, Sabry FF, Tao S (2000) Calcaneus fractures with subluxation of the posterior facet. A surgical indication. Clin Orthop Relat Res 377:210-216 